\title{
SMALL SHIPS MANOEUVRING ESTIMATION IN PLANNING DOMAIN
}

\author{
Dan Obreja \\ "Dunarea de Jos" University of Galati, \\ Faculty of Naval Architecture, Galati, Domneasca \\ Street, No. 47, 800008, Romania, \\ E-mail:dan.obreja@ugal.ro
}

\begin{abstract}
The estimation of the small ships manoeuvring performance in the planning domain represents an important aspect related to the initial design stage. The turning circle characteristics can be determined by using the method proposed by Mordvinov. Based on this method, a computer code was performed in the Research Centre of the Naval Architecture Faculty from "Dunarea de Jos" University of Galati. Practical result obtained on a planning small ship with outboard engines is presented in this paper. The computer code was integrated in the PHP software platform, dedicated to the estimation of the ships hydrodynamics performances, in the case of didactical applications or research activities.
\end{abstract}

Keywords: small ships, planning domain, turning circle, computer code

\section{INTRODUCTION}

The prediction of the hydrodynamics performances of the small ships in planning domain represents an important task of the design offices.

The problem of the small ship resistance estimation in planning domain was analysed in a previous paper [4].

Also, the problem of the small ship manoeuvring estimation in displacement domain was studied [5].

In this paper, the practical evaluation of the turning circle characteristics in the case of the small ships, with outboard engines, in planning domain was discussed, based on the mathematical model proposed by Mordvinov ([1], [2]).

A specific computer code was developed in the Research Centre of the Naval Architecture Faculty in "Dunarea de Jos" University of Galati, in order to calculate the manoeuvring performance of the small ships with outboard engines, in planning domain, by using the mentioned method [6].

A practical application was presented, in order to estimate the steady turning diameter and the heeling angle of a small ship in planning domain, having $6 \mathrm{~m}$ in length.

The summary of the Mordvinov mathematical model is presented in the following chapter.

\section{THEORETICAL METHOD}

On the basis of the Mordvinov method, the nondimensional steady turning diameter $\bar{D}$ of a planning small ship can be determined, by using the following relation

$$
\bar{D}=\frac{2}{\bar{\omega}_{B}} \cdot \frac{B_{T_{p}}}{L}
$$

where $\bar{\omega}_{B}$ is the nondimensional angular speed, $L$ is the ship length and $B_{T_{p}}$ is the beam of the transom stern.

The nondimensional angular speed $\bar{\omega}_{B}$ is given by the relation 


$$
\bar{\omega}_{B}=\frac{C_{Y}^{a} \cdot \delta_{R}}{C_{Y_{B}}^{\beta}} \cdot \frac{e_{1}}{e_{2}}
$$

where, $\delta_{R}$ is the deflection angle of the outboard engine, $C_{Y}^{a}$ is the derivative of the hydrodynamic coefficient of lateral force and $C_{Y_{B}}^{\beta}$ is the hydrodynamic derivative of the planning hull in function of the drift angle $\beta$.

The expressions $e_{1}$ and $e_{2}$ ([1], [2]) depend on the hydrodynamic derivative $C_{Y_{B}}^{\omega}$ of the planning hull in function of the angular speed $\omega$, the trim angle in planning domain $\theta_{2}$ and the Froude number $F_{n B}$ calculated with beam of the transom stern $B_{T p}$, ship speed $v$ and gravity acceleration $g$

$$
F_{n B}=\frac{v}{\sqrt{g \cdot B_{T p}}}
$$

Also, during the turning circle manoeuvre, the heeling angle $\phi$ can be estimated by using the following expression

$$
\phi=\frac{C_{Y}^{a} \cdot \delta_{R}}{C_{Y_{B}}^{\beta}} \cdot \frac{e_{3}}{e_{2}}
$$

where, $e_{3}$ depends by the hydrodynamics derivatives of the planning hull $C_{Y_{B}}^{\omega}$ and $C_{Y_{B}}^{\beta}$ ([1], [2]).

The calculation of the hydrodynamics derivatives can be performed by using the Mordvinov relations ([1], [2]).

On the basis of this mathematical model, the computer code PHP NM-MAN-G was realised in the Research Centre of the Naval Architecture Faculty from "Dunarea de Jos" University of Galati [6].

This code was integrated on the in house PHP software platform (Preliminary Hydrodynamics Performance) and can be used for didactical applications [3] or research activities.

\section{PRACTICAL EVALUATION}

Practical results obtained on a planning small ship having $6 \mathrm{~m}$ in length were presented in this chapter.
Table 1 presents the main characteristics of the small ship.

Table 1. Main characteristics of the small ship

\begin{tabular}{|l|c|}
\hline \hline \multicolumn{1}{|c|}{ Main characteristics } & Value \\
\hline \hline Ship length, $L[\mathrm{~m}]$ & 6.0 \\
\hline Wetted length of the bottom, $l_{c m}[\mathrm{~m}]$ & 4.1 \\
\hline Beam of the transom stern, $B_{T_{p}}[\mathrm{~m}]$ & 2.0 \\
\hline Medium draught, $T[\mathrm{~m}]$ & 0.25 \\
\hline Design speed, $v[\mathrm{Km} / \mathrm{h}]$ & 35 \\
\hline Block coefficient, $C_{B}$ & 0.5 \\
\hline Prismatic coefficient, $C_{P}$ & 0.77 \\
\hline $\begin{array}{l}\text { Longitudinal center of gravity from } \\
\text { midship section, } x_{G}[\mathrm{~m}]\end{array}$ & 0 \\
\hline Vertical center of gravity, $z_{G}[\mathrm{~m}]$ & 0.7 \\
\hline Deadrise angle at midship, $\beta_{0}[\mathrm{deg}]$. & 12.0 \\
\hline Trim angle at zero speed $\theta_{l}[\mathrm{deg}]$. & -1.0 \\
\hline Trim angle at design speed $\theta_{2}[\mathrm{deg}]$. & 2.5 \\
\hline Propeller diameter, $D_{P}[\mathrm{~m}]$ & 0.25 \\
\hline Propeller thrust, $T_{p}[\mathrm{kN}]$ & 1.0 \\
\hline $\begin{array}{l}\text { Vertical distance from the propeller } \\
\text { shaft to the center of gravity, } z_{p}[\mathrm{~m}]\end{array}$ & 0.9 \\
\hline Wake fraction, $w$ & 0.15 \\
\hline Number of the outboard engines, $n_{B}$ & 2 \\
\hline
\end{tabular}

In the case of the positive trim angle, the aft immersion occurs.

The main output data provided by the computer code are presented in Table 2.

Figures 1 and 2 depict the diagrams of the steady turning diameter and heeling angle respectively, depending by the deflection angle of the outboard engine.

Table 2. Turning circle results

\begin{tabular}{|c|c|c|}
\hline $\begin{array}{c}\text { Deflection } \\
\text { angle } \\
\delta_{\mathrm{R}} \\
\text { [deg.] }\end{array}$ & $\begin{array}{c}\text { Steady } \\
\text { turning } \\
\text { diameter } \\
\bar{D}\end{array}$ & $\begin{array}{c}\text { Heeling } \\
\text { angle } \\
\phi \\
\text { [deg.] }\end{array}$ \\
\hline 0 & - & 0. \\
\hline 5 & 71.4 & 2.3 \\
\hline 10 & 35.7 & 4.5 \\
\hline 15 & 23.8 & 6.8 \\
\hline 20 & 17.8 & 9.0 \\
\hline 25 & 14.3 & 11.3 \\
\hline 30 & 11.9 & 13.6 \\
\hline 35 & 10.2 & 15.8 \\
\hline 40 & 8.9 & 18.1 \\
\hline
\end{tabular}




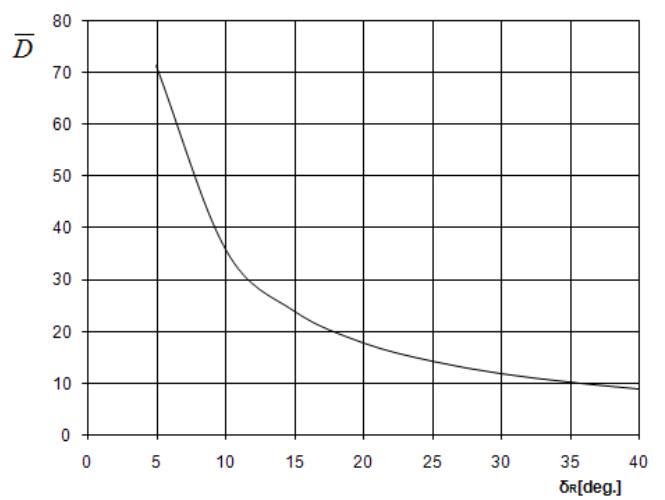

Fig. 1. Nondimensional steady turning diameter

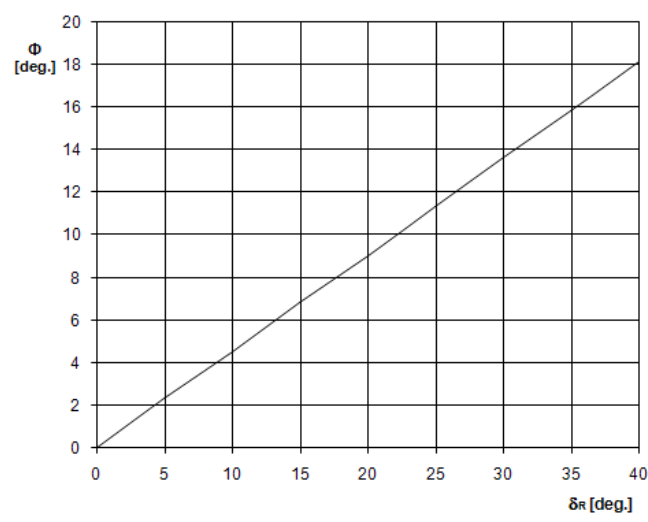

Fig. 2. Heeling angle in the steady turning motion

When the deflection angle of the outboard engine increases, the steady turning diameter decreases and the heeling angle increases. Important values of the steady turning diameter and heeling angle can be observed in the case of the deflection angle $\delta_{\mathrm{R}}=35 \mathrm{deg}$.

The influence of the speed on the turning circle diameter was analysed on the basis of this computer code. The results are presented in Table 3 and Fig. 3 . The Froude number $F_{n}$ was determined by using the following relation

$$
F_{n}=\frac{v}{\sqrt{g \cdot L}}
$$

An important increase of the steady turning diameter was observed, if the ship speed increase, in the domain of the large Froude numbers.

Table 3. Speed influence on the steady turning diameter $\left(\delta_{R}=35 \mathrm{deg}\right.$. $)$

\begin{tabular}{|c|c|c|}
\hline $\begin{array}{c}\text { Ship } \\
\text { speed } \\
v \\
{[\mathrm{Km} / \mathrm{h}]}\end{array}$ & $\begin{array}{c}\text { Froude } \\
\text { number } \\
F n\end{array}$ & $\begin{array}{c}\text { Steady } \\
\text { turning } \\
\text { diameter } \\
\bar{D}\end{array}$ \\
\hline 25.0 & 0.905 & 3.4 \\
\hline 27.5 & 0.995 & 4.7 \\
\hline 30. & 1.085 & 6.3 \\
\hline 32.5 & 1.176 & 8.1 \\
\hline 35.0 & 1.267 & 10.2 \\
\hline
\end{tabular}

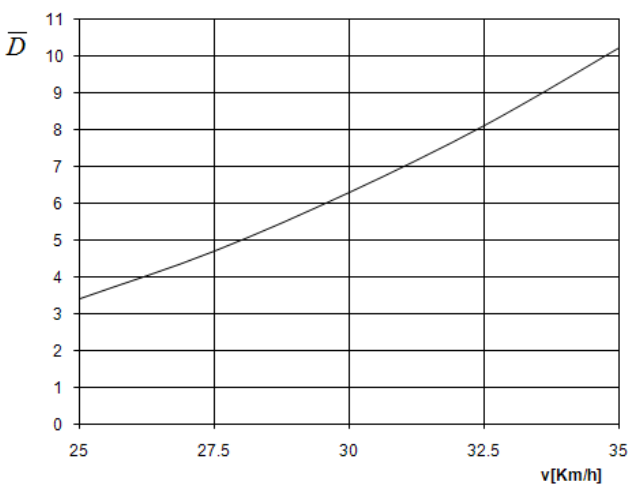

Fig. 3. Nondimensional steady turning diameter $\left(\delta_{R}=35\right.$ deg. $)$. Speed influence

Also, the influence of the deadrise angle at midship section $\beta_{0}$ on the steady turning diameter was determined. The results are presented in Table 4 and Fig. 4.

Table 4. Deadrise angle influence on the steady turning diameter $\left(\delta_{\mathrm{R}}=35 \mathrm{deg}\right.$. $)$

\begin{tabular}{|c|c|}
\hline $\begin{array}{c}\text { Deadrise } \\
\text { angle } \\
\beta_{0} \\
\text { [deg.] }\end{array}$ & $\begin{array}{c}\text { Steady } \\
\text { turning } \\
\text { diameter } \\
\bar{D}\end{array}$ \\
\hline 8. & 11.6 \\
\hline 10. & 10.7 \\
\hline 12. & 10.2 \\
\hline 14. & 10.3 \\
\hline 16. & 11.8 \\
\hline
\end{tabular}

One can note that the optimal value of the deadrise angle $\left(\beta_{0}=12 \mathrm{deg}\right.$.) related to the criterion of minimum steady turning diameter represents, in the same time, the adopted input data at the analysed small ship. 


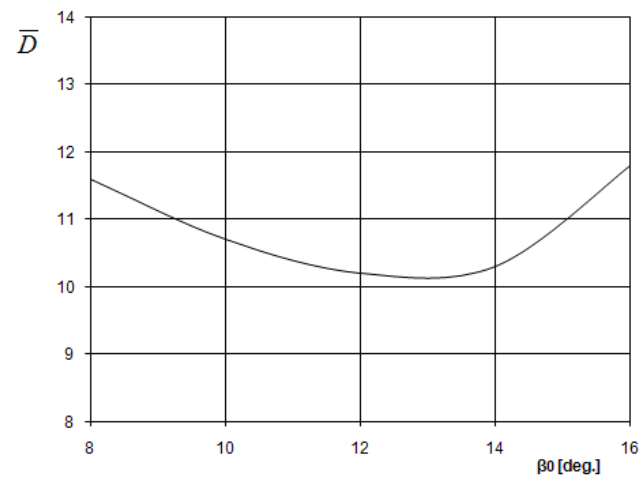

Fig. 4. Nondimensional steady turning diameter $\left(\delta_{R}=35\right.$ deg. $)$. Deadrise angle influence

\section{CONCLUDING REMARKS}

The prediction of the manoeuvring performance of the small ships in the planning domain represents an important aspect starting to the initial design stage.

The turning circle characteristics in the planning domain of the small ship with outboard engines can be estimated by using the method proposed by Mordvinov.

A computer code was performed in the Research Centre of the Naval Architecture Faculty from "Dunarea de Jos" University of Galati, based on this method.

Practical results obtained on a planning small ship with $6 \mathrm{~m}$ in length were presented in this paper. The nondimensional steady turning diameter and the heeling angle were estimated, depending by the deflection angle of the outboard engine. The influence of the ship speed and deadrise angle were also established.

The computer code was integrated in the PHP in house software platform (Preliminary Hydrodynamics Performance), intended for the estimation of the ships hydrodynamics performances and can be used for didactical application and research activities.

\section{Acknowledgements}

The paper was supported by the Research Centre of the Naval Architecture Faculty in "Dunarea de Jos" University of Galati.

The computer code in Java language was developed by Mr. George Jagite, during your bachelor student activities.

\section{REFERENCES}

[1]. Mordvinov, B.G., "Spravocinic po malotonajnomu sudostroeniu”, $\mathrm{Su}$ dostroenie Publishing House, St. Petersburg, 1988 (in Russian).

[2]. Obreja, C.D., "Hydrodynamic particularities of the small ships design”, The University Foundation "Dunarea de Jos" Publishing House, Galati, 2004 (in Romanian).

[3]. Obreja, C.D., Pacuraru, S., "Small ships hydrodynamics. Numerical Laboratory", The University Foundation "Dunarea de Jos" Publishing House, Galati, 2016 (in Romanian).

[4]. Obreja, C.D., "Small ships resistance estimation in planning domain", The Annals of "Dunarea de Jos" University of Galati, Fascicle XI - Shipbuilding, pp. 49-54, 2017.

[5]. Obreja, C.D., "Small ships manoeuvring estimation in displacement domain", The Annals of "Dunarea de Jos" University of Galati, Fascicle XI - Shipbuilding, pp. 31-36, 2017.

[6]. Obreja, C.D., Jagite, G, "PHP NM$M A N-G$ ", The Research Centre of the Naval Architecture Faculty in "Dunarea de Jos” University of Galati, 2016.

Paper received on December $14^{\text {th }}, 2018$ 